\title{
Continuous-flow synthesis of highly functionalized imidazo-oxadiazoles facilitated by microfluidic extraction
}

\author{
Ananda Herath and Nicholas D. P. Cosford ${ }^{*}$
}

\author{
Full Research Paper \\ Address: \\ Cancer Metabolism \& Signaling Networks Program, Sanford Burnham \\ Prebys Medical Discovery Institute, 10901 North Torrey Pines Road, \\ La Jolla, California 92037, USA \\ Email: \\ Nicholas D. P. Cosford - ncosford@sbpdiscovery.org \\ * Corresponding author \\ Keywords: \\ imidazo[1,2-a]pyridine; imidazo[1,2-a]pyridin-2-yl-1,2,4-oxadiazole; \\ liquid-liquid extraction module; microreactor; 1,2,4-oxadiazole
}



Beilstein J. Org. Chem. 2017, 13, 239-246.

doi:10.3762/bjoc. 13.26

Received: 01 October 2016

Accepted: 06 January 2017

Published: 07 February 2017

This article is part of the Thematic Series "Automated chemical synthesis".

Guest Editor: I. R. Baxendale

(C) 2017 Herath and Cosford; licensee Beilstein-Institut.

License and terms: see end of document.

Open Access

\begin{abstract}
A versatile continuous-flow synthesis of highly functionalized 1,2,4-oxadiazoles starting from carboxylic acids is reported. This process was applied to the multistep synthesis of imidazo[1,2-a]pyridin-2-yl-1,2,4-oxadiazoles, using a three reactor, multistep continuous-flow system without isolation of intermediates. This continuous-flow method was successfully combined with a single-step liquid-liquid microextraction unit to remove high boiling point polar solvents and impurities and provides the target compounds in high purity with excellent overall yields.
\end{abstract}

\section{Introduction}

The design and execution of scalable and economically viable processes for the preparation of biologically active small molecules is a major hurdle in modern organic synthesis. The development of batch processes that combine multiple reactions into "one-pot" have been used successfully in some cases [1-6]. However, this approach has a number of drawbacks, primarily because of mutual interference between various reactive components. Recently, continuous-flow chemistry has emerged as a powerful technique in organic synthesis. This is in part due to the potential for integrating individual reaction steps and subsequent separations into a single streamlined process [7-14].
On the other hand, a significant challenge in flow chemistry is the formation of insoluble intermediates in the reactor. This can often be prevented by using polar organic solvents such as dimethylformamide (DMF) [7-9,15]. However, the challenges of removing large amounts of high boiling solvents during the purification and isolation process can limit scalability and efficiency. Furthermore, many useful synthetic reactions are incompatible with the use of DMF as a solvent. Recently several unit operations have successfully been implemented in continuous-flow syntheses to allow separations and purifications in a continuous fashion, such as liquid-liquid microextrac- 
tion [12,16-20] or microfluidic distillation [21,22]. Herein we describe the utilization of liquid-liquid microextraction to facilitate a complex, multistep flow synthesis process.

Our research in the field of flow synthesis has focused on developing continuous-flow chemistry methods to access complex, drug-like molecules from readily available precursors without isolation of intermediates. We have shown that the "telescoping" of multiple synthetic steps into a single continuous process provides an efficient method for the production of heterocyclic compound libraries in sufficient quantities for biological screening in high-throughput assay formats as well as follow-up confirmatory studies. We previously reported a method for the preparation of 1,2,4-oxadiazoles in an uninterrupted continuous-flow sequence using arylnitriles and acyl chloride precursors [9]. We also reported the flow synthesis of highly functionalized imidazo[1,2- $a$ ] heteroaryl derivatives from readily available starting materials in a single continuous process [7]. We now report an efficient continuous-flow procedure for the synthesis of 1,2,4-oxadiazoles directly from arylnitriles and carboxylic acid derivatives. We further demonstrate the incorporation of this procedure into a continuous, threemicroreactor method for the highly efficient preparation of a diverse library of imidazo-oxadiazole derivatives. Moreover, this continuous-flow method was successfully combined with a single-step liquid-liquid microextraction unit to remove high boiling point polar solvents and impurities.

\section{Results and Discussion}

Historically the 1,2,4-oxadiazole scaffold has been used by medicinal chemists as a ubiquitous bioisosteric replacement of amide and ester functionalities in a wide variety of biologically active compounds $[23,24]$. This motif is found in several drugs and drug leads including sphingosine-1-phosphate $1\left(\mathrm{~S}_{1} \mathrm{P}_{1}\right)$ receptor agonists [25-27] and metabotropic glutamate subtype 5 $\left(\mathrm{mGlu}_{5}\right)$ receptor negative allosteric modulators (NAMs) [25,28-30]. Most synthetic efforts toward the preparation of these heterocyclic systems utilize a multistep, in-flask approach as illustrated by the synthesis of $\mathrm{S}_{1} \mathrm{P}_{1}$ agonists (Scheme 1). Thus, a typical batch synthesis entails the formation of an amidoxime by reacting an arylnitrile with hydroxylamine in the presence of a base [29-31]. The amidoxime is then combined with a carboxylic acid derivative in the presence of a coupling reagent. The target oxadiazole is then formed via an intramolecular cyclodehydration (Scheme 1) [27,32-34].

For our initial studies on the development of a flow synthesis of 1,2,4-oxadiazoles we focused on the reaction of $N$-hydroxynicotinimidamide with 3-bromobenzoic acid (Table 1). Screening a variety of reaction conditions using a single microreactor we found that the combination of EDC/HOBt/DIPEA (1:1:1) for $10 \mathrm{~min}$ at $150{ }^{\circ} \mathrm{C}$ provided the best conditions for complete conversion of 3-bromobenzoic acid to the corresponding 1,2,4oxadiazole derivative (Table 1 , entry 5). The use of $N, N$ dimethylformamide (DMF) as a solvent resulted in competitive amide formation from the decomposition product of DMF at high temperature. In order to prevent this we switched to $\mathrm{N}, \mathrm{N}$ dimethylacetamide (DMA) as the solvent.

We next focused our efforts on combining this optimized oxadiazole ring-closure procedure with our previously reported flow synthesis of amidoximes by the reaction of hydroxylamine with precursor aryl- and heteroarylnitriles (Table 2). These two reactions were successfully perfomed in flow with slight modifications to the reaction conditions to generate a variety of 1,2,4oxadiazoles (Table 2). Reactions of arylnitriles having electron-

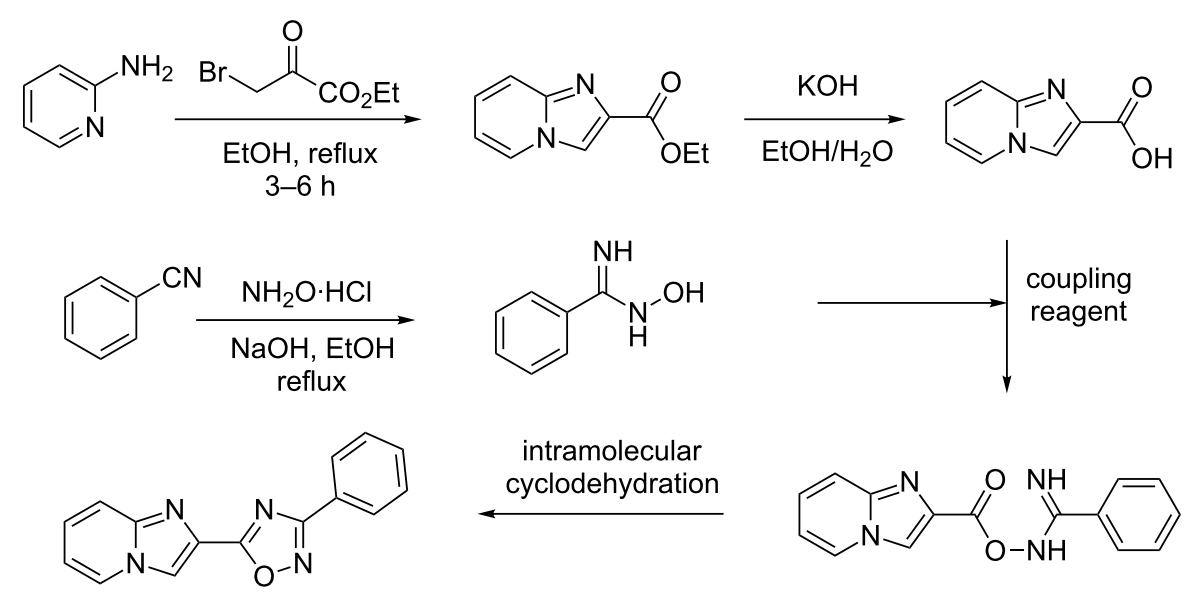

Scheme 1: In-flask (batch) preparation of imidazo[1,2-a]pyridin-2-yl-1,2,4-oxadiazoles (S1P 1 agonists) [27]. 


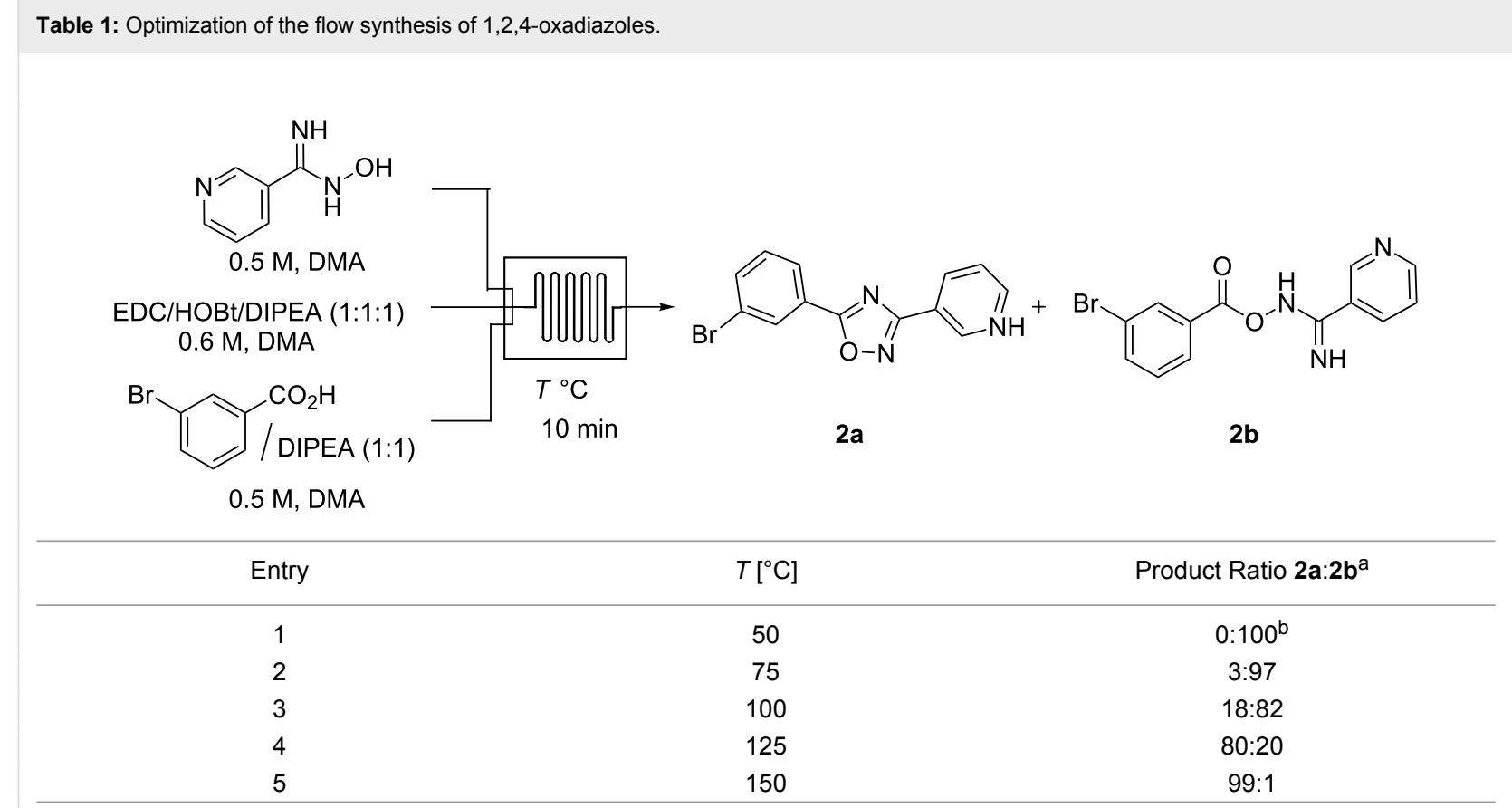

${ }^{a}$ Compound ratios were determined using LC-MS (see Figure S1 in Supporting Information File 1). ${ }^{b}$ Compound 2 a was not observed.

donating (Table 2, entry 7) or electron-withdrawing groups (Table 2, entries 1, 2, 4 and 8) proceeded efficiently in good to excellent overall yields. Additionally, a range of aliphatic and aromatic acids were tolerated under these reaction conditions to produce the corresponding oxadiazoles in high yields. Several advantages of this methodology compared to our previously reported flow synthesis should be noted. First, this method is more facile because no cooling step is necessary before flowing into the second microreactor. Secondly, many more carboxylic acid derivatives are readily available (purchased or easily synthesized) than acyl chlorides allowing access to greater diversity. Finally, this method is easily adapatable to the synthesis of compounds with increasing complexity, as shown by our next set of experiments.

To demonstrate the utility of the newly developed methodology, our next goal was to incorporate a carboxylic acid synthesis step into the flow process. As noted above, we previously reported the continuous-flow synthesis of imidazo[1,2- $a$ ]pyridine-2carboxylic acids in a single, uninterrupted process directly from readily available starting materials. We hypothesized that incorporating this step into our new oxadiazole synthesis would provide access to diverse imidazo[1,2-a]pyridin-2-yl-1,2,4oxadiazoles of biological importance [27]. The flow platform we were using, the Syrris AFRICA ${ }^{\circledR}$ flow system, is limited to two heated reactors. To overcome this issue a third reactor was placed in a heated silicone oil bath and a flow system was assembled as shown in Table 3 . The first reaction, the formation of imidazo[1,2-a]pyridine-2-carboxylic acid, was performed in a $1000 \mu \mathrm{L}$ reactor (glass chip) at $100{ }^{\circ} \mathrm{C}$. The acid exiting the first reactor was combined with EDC/HOBt/DIPEA $(1: 1: 1)$ in a T-mixer. The synthesis of amidoxime was achieved by placing a second reactor $(250 \mu \mathrm{L}$ glass chip) in a heated silicone oil bath at $100{ }^{\circ} \mathrm{C}$. The product stream was next introduced into a third reactor $(1000 \mu \mathrm{L})$ and mixed with the stream exiting from the T-mixer at $150{ }^{\circ} \mathrm{C}$. Initial studies suggested that premixing of acid and coupling reagent was efficient and provided better yields. The substrate scope of this continuous flow method is shown in Table 3. Thus, this flow method delivers a diverse array of drug-like heterocycles in good overall yields.

Although this multistep continuous-flow method allowed the construction of complex molecules rapidly without the need for purification and isolation of intermediates, lower flow rates and small reactors limited the scalability of the method. As noted previously, the use of high boiling point solvents, such as DMA, are less attractive during scale-up due to the difficulty of removal of these solvents during purification. Consequently the current method is limited to small scale library synthesis. Therefore, our next goal was to convert this microfluidic procedure to a sequence that would deliver compounds on a larger scale. To this end, we first focused our attention on increasing the throughput of the reaction by using the larger tubing and tube 
Table 2: Synthesis of 1,2,4-oxadiazoles via a continuous microreactor sequence from arylnitriles and carboxylic acids.



Entry Yield (\%) $)^{\mathrm{a}}$

alsolated yield after chromatographic purification of the crude reaction mixture.

reactors available in the Vapourtec $\mathrm{R}$ series flow system. We also increased the flow rate to maintain a residence time of $12 \mathrm{~min}$ in the third reactor (Scheme 2). Next, a microfluidic liquid-liquid extraction module (the AFRICA ${ }^{\circledR}$ FLLEX) was incorporated at the end of the flow sequence to remove the high boiling point solvent (DMA). Initial studies using a single microreactor and dichloromethane as the organic extraction phase demonstrated proof-of-concept that the microfluidic extraction could be used in the oxadiazole flow synthesis procedure (see Supporting Information File 1). However, the optimized method employs the introduction of toluene and water into the microfluidic extraction module to efficiently remove the DMA and avoid the use of a halogenated solvent, as shown in Scheme 2 and Scheme 3. The reaction mixture exiting from the third reactor is mixed with water and toluene using an external pump before entering the phase separation device. On a preparative scale using this flow reaction setup, the desired oxadiazole derivatives were obtained in good yield with a throughput of $\sim 0.5 \mathrm{~g} / \mathrm{h}$. To demonstrate the utility of this new method we synthesized the mGlu $_{5}$ NAM (Table 2, entry 3 ) on a gram scale in high yield $(3.5 \mathrm{~g}, 70 \%)$. With the same optimized flow method we also synthesized 5-(6-bromoimidazo[1,2a]pyridin-2-yl)-3-(4-chlorophenyl)-1,2,4-oxadiazole on a gram scale ( 2 g, $42 \%)$ rapidly and efficiently (Scheme 3 ).

Several advantages of this methodology compared to the standard batch synthesis should be noted. First, a fully automated flow method permits the rapid construction of libraries of highly functionalized oxadiazole derivatives. Second, imidazo[1,2- $a$ ]pyridin-2-yl-1,2,4-oxadiazoles, a scaffold with activity as $\mathrm{S}_{1} \mathrm{P}_{1}$ agonists, are prepared directly from commercially available building blocks in a single continuous process without isolating intermediates. As noted previously, the standard in-flask (batch) synthesis of these compounds involves multiple reaction steps requiring work-up and purification of several intermediates. Furthermore, liquid-liquid microextrac- 
Table 3: Continuous-flow process for the synthesis of imidazo[1,2-a]pyridin-2-yl-1,2,4-oxadiazoles.



alsolated yield after chromatographic purification of the crude reaction mixture.

tion removes high boiling point solvent and impurities from the product. Finally, this new process with liquid-liquid extraction allows easy scale-up and eliminates the tedious high boiling point solvent removal step.

\section{Conclusion}

In summary, we have developed a telescoped continuous-flow method for the synthesis of diversely substituted imidazo[1,2a]pyridine-2-yl-1,2,4-oxadiazole derivatives directly from com- 



Scheme 3: Gram-scale synthesis of imidazo[1,2-a]pyridin-2-yl-1,2,4-oxadiazole $\mathrm{S}_{1} \mathrm{P}_{1}$ agonist scaffold by continuous flow combined with microfluidic extraction.

mercial nitriles, aminopyridine carboxylic acids and hydroxylamine. Moreover, we demonstrated that a liquid-liquid microextraction unit can be utilized to remove high polar water soluble solvents and impurities from products. This scalable method provides the desired oxadiazole derivatives at a rate of $\approx 0.5 \mathrm{~g} / \mathrm{h}$ and represents a significant advantage over batch synthesis. We anticipate that these advances will facilitate the rapid synthesis of these biologically important compounds.

\section{Experimental}

All reagents were used as received unless otherwise noted. ${ }^{1} \mathrm{H}$ and ${ }^{13} \mathrm{C}$ spectra were obtained in $\mathrm{CDCl}_{3}$ at room temperature, unless otherwise noted, on a JEOL (JNM-CS400) $400 \mathrm{MHz}$ instrument. Chemical shifts of ${ }^{1} \mathrm{H}$ NMR spectra were recorded in parts per million (ppm) on the $\delta$ scale from an internal standard of residual $\mathrm{CDCl}_{3}$ (7.24 ppm). Chemical shifts of ${ }^{13} \mathrm{C}$ NMR spectra were recorded in ppm from the central peak of $\mathrm{CDCl}_{3}$ (77.0 ppm) on the $\delta$ scale. High-resolution ESI-TOF mass spectra were acquired from the Mass Spectrometry Core at the Sanford Burnham Prebys Medical Discovery Institute (Orlando, Florida). LC-MS analyses were carried out on a Shimadzu LC-MS 2010 Series LC System with a Kromasil 100 5 micron $\mathrm{C} 18$ column $(50 \times 2.1 \mathrm{~mm}$ i.d. $)$. Continuous-flow (microreactor) experiments were carried out using a Syrris AFRICA apparatus or a Vapourtec R Series Flow Chemistry System. 
General procedure for the optimization of the flow synthesis of 1,2,4-oxadiazoles (Table 1)

The reaction was conducted in a glass reactor consisting of a $1.0 \mathrm{~mL}$ retention unit and three inlets. Streams of EDC/HOBt/ DIPEA (1:1:1, $25 \mu \mathrm{L} / \mathrm{min}, 0.6 \mathrm{M}$, DMA), acid/DIPEA ( $1: 1$, $25 \mu \mathrm{L} / \mathrm{min}, 0.5 \mathrm{M}, \mathrm{DMA})$ and a solution of amidoximes ( $25 \mu \mathrm{L} / \mathrm{min}, 0.5 \mathrm{M}$, DMA) were combined in the glass reactor at different temperatures for $10 \mathrm{~min}$ of residence time. Reactions were monitored by LC-MS analysis and showed that the conversion of the 3-bromobenzoic acid to the corresponding 1,2,4-oxadiazole was optimal at $150^{\circ} \mathrm{C}$ (Table 1 , entry 5).

\section{General procedure for the synthesis of 1,2,4- oxadiazoles via a continuous microreactor sequence from arylnitriles and acids (Table 2)}

A solution of $\mathrm{ArCN} / \mathrm{NH}_{2} \mathrm{OH} \cdot \mathrm{HCl} / \mathrm{DIPEA}(1.05: 1: 3,0.4 \mathrm{M}$, DMA) was introduced to a glass microreactor $(250 \mu \mathrm{L})$ heated at $100{ }^{\circ} \mathrm{C}$. The stream exiting from the first reactor was combined with streams of the acid/DIPEA $(1: 1,25.0 \mu \mathrm{L} / \mathrm{min}$, $0.5 \mathrm{M}, \mathrm{DMA})$ and EDC/HOBt/DIPEA $(1: 1: 1,25 \mu \mathrm{L} / \mathrm{min}$, $0.6 \mathrm{M}, \mathrm{DMA})$ in a second glass reactor $(1.0 \mathrm{~mL})$ at $150{ }^{\circ} \mathrm{C}$ for $15 \mathrm{~min}$ of residence time. This reaction was carried out with a back pressure of 4.0 bar. The reaction mixture was mixed with excess water and extracted three times with dichloromethane. The combined organic layers were washed with brine, dried over magnesium sulfate, filtered, and concentrated and the residue was purified via automated flash chromatography $\left(\mathrm{SiO}_{2}\right)$ to afford the desired product (CombiFlash ${ }^{\circledR} \mathrm{Rf}, 12 \mathrm{~g}$ flash column). The solvent gradient was $90 \%$ hexane to $50 \%$ ethyl acetate over $15 \mathrm{~min}$ at a flow rate of $15 \mathrm{~mL} / \mathrm{min}$.

\section{General procedure for the continuous flow synthesis of imidazo[1,2-a]pyridin-2-yl-1,2,4- oxadiazoles (Table 3)}

The first reaction, the formation of imidazo[1,2- $a]$ pyridine-2carboxylic acid, was carried out in a $1000 \mu \mathrm{L}$ reactor (glass chip) at $100{ }^{\circ} \mathrm{C}$. The acid exiting the first reactor was combined with EDC/HOBt/DIPEA (1:1:1, $0.5 \mathrm{M}$, DMA) in a T-mixer. The synthesis of amidoxime $\left(\mathrm{ArCN} / \mathrm{NH}_{2} \mathrm{OH} \cdot \mathrm{HCl} / \mathrm{DIPEA}\right.$ (1.1:1:3), 0.4 M, DMA) was achieved by placing a second reactor $(250 \mu \mathrm{L}$ glass chip) in a heated silicone oil bath at $100{ }^{\circ} \mathrm{C}$. This stream was next introduced into a third reactor and mixed with the stream exiting from the T-mixer at $150{ }^{\circ} \mathrm{C}$. The stream exiting the third chip was collected after passing through the back pressure regulator. This reaction was carried out with a back pressure of 4.0 bar. The reaction mixture was mixed with excess water and extracted three times with dichloromethane. The combined organic layers were washed with brine, dried over magnesium sulfate, filtered, and concentrated and the residue was purified via automated flash chromatography $\left(\mathrm{SiO}_{2}\right)$ to afford the desired product (CombiFlash ${ }^{\circledR} \mathrm{Rf}, 12 \mathrm{~g}$ flash column). The solvent gradient was $90 \%$ hexane to $50 \%$ ethyl acetate over $15 \mathrm{~min}$ at a flow rate of $15 \mathrm{~mL} / \mathrm{min}$.

\section{Supporting Information}

LC traces for optimization of oxadiazole synthesis (Table 1), details of liquid-liquid microextraction with FLLEX module including LC traces, general and detailed synthetic procedures with full characterization data for compounds, and ${ }^{1} \mathrm{H}$ NMR and ${ }^{13} \mathrm{C}$ NMR spectral traces of all compounds.

\section{Supporting Information File 1 \\ Experimental data. \\ [http://www.beilstein-journals.org/bjoc/content/ supplementary/1860-5397-13-26-S1.pdf]}

\section{Acknowledgements}

The authors thank Drs. Dhanya Panickar, Douglas Sheffler and Peter Teriete for their help editing the manuscript. This work was supported by National Institutes of Health grant nos. HG005033, GM079590, and GM081261.

\section{References}

1. Hansen, K. B.; Hsiao, Y.; Xu, F.; Rivera, N.; Clausen, A.; Kubryk, M.; Krska, S.; Rosner, T.; Simmons, B.; Balsells, J.; Ikemoto, N.; Sun, Y.; Spindler, F.; Malan, C.; Grabowski, E. J. J.; Armstrong, J. D., III. J. Am. Chem. Soc. 2009, 131, 8798-8804. doi:10.1021/ja902462q

2. Broadwater, S. J.; Roth, S. L.; Price, K. E.; Kobašlija, M.; McQuade, D. T. Org. Biomol. Chem. 2005, 3, 2899-2906. doi:10.1039/b506621m

3. Hyde, A. M.; Buchwald, S. L. Angew. Chem., Int. Ed. 2008, 47, 177-180. doi:10.1002/anie.200704529

4. Tietze, L. F.; Brasche, G.; Gericke, K. M. Domino Reactions in Organic Synthesis; Wiley: Weinheim, 2006. doi:10.1002/9783527609925

5. Tietze, L. F. Chem. Rev. 1996, 96, 115-136. doi:10.1021/cr950027e

6. Enders, D.; Grondal, C.; Hüttl, M. R. M. Angew. Chem., Int. Ed. 2007, 46, 1570-1581. doi:10.1002/anie.200603129

7. Herath, A.; Dahl, R.; Cosford, N. D. P. Org. Lett. 2010, 12, 412-415. doi:10.1021/ol902433a

8. Herath, A.; Cosford, N. D. P. Org. Lett. 2010, 12, 5182-5185. doi:10.1021/ol102216x

9. Grant, D.; Dahl, R.; Cosford, N. D. P. J. Org. Chem. 2008, 73, 7219-7223. doi:10.1021/jo801152c

10. Baxendale, I. R.; Ley, S. V.; Mansfield, A. C.; Smith, C. D. Angew. Chem., Int. Ed. 2009, 48, 4017-4021. doi:10.1002/anie.200900970

11. Usutani, H.; Tomida, Y.; Nagaki, A.; Okamoto, H.; Nokami, T.; Yoshida, J.-i. J. Am. Chem. Soc. 2007, 129, 3046-3047. doi:10.1021/ja068330s

12. Sahoo, H. R.; Kralj, J. G.; Jensen, K. F. Angew. Chem., Int. Ed. 2007, 46, 5704-5708. doi:10.1002/anie.200701434 
13. Bogdan, A. R.; Mason, B. P.; Sylvester, K. T.; McQuade, D. T. Angew. Chem., Int. Ed. 2007, 46, 1698-1701. doi:10.1002/anie.200603854

14. Webb, D.; Jamison, T. F. Chem. Sci. 2010, 1, 675-680. doi:10.1039/c0sc00381f

15. Pagano, N.; Herath, A.; Cosford, N. D. P. J. Flow Chem. 2011, 1, 28-31. doi:10.1556/jfchem.2011.00001

16. Aota, A.; Nonaka, M.; Hibara, A.; Kitamori, T. Angew. Chem., Int. Ed. 2007, 46, 878-880. doi:10.1002/anie.200600122

17. Kralj, J. G.; Sahoo, H. R.; Jensen, K. F. Lab Chip 2007, 7, 256-263. doi:10.1039/B610888A

18. Dessimoz, A.-L.; Cavin, L.; Renken, A.; Kiwi-Minsker, L. Chem. Eng. Sci. 2008, 63, 4035-4044. doi:10.1016/j.ces.2008.05.005

19. Maruyama, T.; Matsushita, H.; Uchida, J.-i.; Kubota, F.; Kamiya, N.; Goto, M. Anal. Chem. 2004, 76, 4495-4500. doi:10.1021/ac049844h

20. Noël, T.; Kuhn, S.; Musacchio, A. J.; Jensen, K. F.; Buchwald, S. L. Angew. Chem., Int. Ed. 2011, 50, 5943-5946. doi:10.1002/anie.201101480

21. Hartman, R. L.; Sahoo, H. R.; Yen, B. C.; Jensen, K. F. Lab Chip 2009, 9, 1843-1849. doi:10.1039/b901790a

22. Hartman, R. L.; Naber, J. R.; Buchwald, S. L.; Jensen, K. F. Angew. Chem., Int. Ed. 2010, 49, 899-903. doi:10.1002/anie.200904634

23. Diana, G. D.; Volkots, D. L.; Nitz, T. J.; Bailey, T. R.; Long, M. A.; Vescio, N.; Aldous, S.; Pevear, D. C.; Dutko, F. J. J. Med. Chem. 1994, 37, 2421-2436. doi:10.1021/jm00041a022

24. Borg, S.; Vollinga, R. C.; Labarre, M.; Payza, K.; Terenius, L.; Luthman, K. J. Med. Chem. 1999, 42, 4331-4342. doi:10.1021/jm990197+

25. Li, Z.; Chen, W.; Hale, J. J.; Lynch, C. L.; Mills, S. G.; Hajdu, R.; Keohane, C. A.; Rosenbach, M. J.; Milligan, J. A.; Shei, G.-J.; Chrebet, G.; Parent, S. A.; Bergstrom, J.; Card, D.; Forrest, M.; Quackenbush, E. J.; Wickham, L. A.; Vargas, H.; Evans, R. M.; Rosen, H.; Mandala, S. J. Med. Chem. 2005, 48, 6169-6173. doi:10.1021/jm0503244

26. Buzard, D.; Han, S.; Thoresen, L.; Moody, J.; Lopez, L.; Kawasaki, A.; Schrader, T.; Sage, C.; Gao, Y.; Edwards, J.; Barden, J.; Thatte, J.; Fu, L.; Solomon, M.; Liu, L.; Al-Shamma, H.; Gatlin, J.; Le, M.; Xing, C.; Espinola, S.; Jones, R. M. Bioorg. Med. Chem. Lett. 2011, 21 , 6013-6018. doi:10.1016/j.bmcl.2011.05.110

27. Canne Bannen, L.; Chan, D. S.-M.; Gu, X.-H.; Mac, M. B.; Ng, S.; Wang, T.-L.; Wang, Y.; Xu, W. Imidazo[1,2-a]pyridine Derivatives, Their Use as S1P1 Agonists and Methods for Their Production. WO Patent WO2010065760 A1, June 10, 2010.

28. Zhang, H.-Z.; Kasibhatla, S.; Kuemmerle, J.; Kemnitzer, W.; Ollis-Mason, K.; Qiu, L.; Crogan-Grundy, C.; Tseng, B.; Drewe, J.; Cai, S. X. J. Med. Chem. 2005, 48, 5215-5223. doi:10.1021/jm050292k

29. Roppe, J.; Smith, N. D.; Huang, D.; Tehrani, L.; Wang, B.; Anderson, J.; Brodkin, J.; Chung, J.; Jiang, X.; King, C.; Munoz, B.; Varney, M. A.; Prasit, P.; Cosford, N. D. P. J. Med. Chem. 2004, 47, 4645-4648. doi:10.1021/jm049828c

30. Van Wagenen Bradford, C.; Stormann, T. M.; Moe, S. T.; Sheehan, S. M.; Mcleod, D. A.; Smith, D. L.; Isaac, M. B.; Slassi, A. Heteropolycyclic Compounds and Their Use as Metabotropic Glutamate Receptor Antagonists. WO Patent WO2001012627, Feb 22, 2001.

31. Eloy, F.; Lenaers, R. Chem. Rev. 1962, 62, 155-183. doi:10.1021/cr60216a003
32. Wang, Y.; Miller, R. L.; Sauer, D. R.; Djuric, S. W. Org. Lett. 2005, 7, 925-928. doi:10.1021/ol050007r

33. Adib, M.; Jahromi, A. H.; Tavoosi, N.; Mahdavi, M.; Bijanzadeh, H. R. Tetrahedron Lett. 2006, 47, 2965-2967. doi:10.1016/j.tetlet.2006.02.102

34. Evans, M. D.; Ring, J.; Schoen, A.; Bell, A.; Edwards, P.; Berthelot, D.; Nicewonger, R.; Baldino, C. M. Tetrahedron Lett. 2003, 44, 9337-9341. doi:10.1016/j.tetlet.2003.10.055

\section{License and Terms}

This is an Open Access article under the terms of the Creative Commons Attribution License

(http://creativecommons.org/licenses/by/4.0), which permits unrestricted use, distribution, and reproduction in any medium, provided the original work is properly cited.

The license is subject to the Beilstein Journal of Organic Chemistry terms and conditions: (http://www.beilstein-journals.org/bjoc)

The definitive version of this article is the electronic one which can be found at: doi: $10.3762 /$ bjoc. 13.26 